\title{
The Metaphor and Translation of the Dish Names in Chinese Food Culture
}

\author{
Caiqiao Huo' ${ }^{1}$ Xiaomei Du${ }^{1}$, Weichen $\mathrm{Gu}^{2}$ \\ ${ }^{1}$ College of Foreign Language Education and International Business, Baoding University, Baoding, China \\ ${ }^{2}$ Foreign Language College, Hebei Normal University, Shijiazhuang, China \\ Email: goofyhuo@163.com
}

How to cite this paper: Huo, C. Q., Du, X. M., \& Gu, W. C. (2020). The Metaphor and Translation of the Dish Names in Chinese Food Culture. Open Journal of Modern Linguistics, 10, 423-428.

https://doi.org/10.4236/ojml.2020.105025

Received: August 31, 2020

Accepted: September 11, 2020

Published: September 14, 2020

Copyright $\odot 2020$ by author(s) and Scientific Research Publishing Inc. This work is licensed under the Creative Commons Attribution International License (CC BY 4.0).

http://creativecommons.org/licenses/by/4.0/

(c) (i) Open Access

\begin{abstract}
China is a country famous for different kinds of delicious food. Chinese people attach great importance to the naming of dishes. With the globalization of the world economy in recent years, the translation of dish names has received more and more attention from domestic scholars and related academic institutions. This kind of cross-language and cultural communication activities involves not only the conversion between language symbols, but also the integration of cultures. Chinese metaphor-loaded dish names are an important feature of Chinese recipe names, which are derived from the concept of food culture of the Chinese nation. Only by grasping the connection between Chinese metaphor-loaded dish names and Chinese traditional culture, can we truly grasp the colorful language phenomena presented in metaphor-loaded dish names. Aiming at solving the translation problems of metaphor-loaded dish names, this paper proposes techniques that can be used in translation, in order to provide reference in food translation and boost the spread of Chinese food culture.
\end{abstract}

\section{Keywords}

Food Culture, Dish Names, Metaphors, Translation Skills

\section{Introduction}

China is a country with extensive and profound food culture, and enjoys a high reputation in the world. In the Chinese people's dietary concept, dishes must have elegant names and allusions, and the stories behind them are countless. Therefore, Chinese people attach great importance to the naming of dishes. They believe that a wonderful dish name is not only a vivid advertising word for the dish, but also an organic part of the dish itself, which can please the spirit and 
satisfy the psychological needs. Driven by this concept, a large number of dish names using metaphors have emerged: names with historical events, myths and legends, image of animals and plants. It can be said that metaphorical naming is an important feature of Chinese recipe names, which contains a strong Chinese culture. Therefore, the translation of Chinese metaphorical dish names includes both linguistic and cultural translation.

\section{Research Background}

Many researchers have conducted related studies on the translation of Chinese food names. Pan Yanqiang discusses the English translation of Chinese dish names from the perspective of functional teleology. He believes that our country's culinary art has a long history, and various cuisine schools are competing for attraction; the names of the dishes are various, and they have local and traditional characteristics, which contain a long history of local culture, traditions and even historical stories. But for a long time, our translation research on dish names has lagged behind, which has affected the smooth exchange of Chinese and foreign food culture. He proposed that the research and discussion on dish name translation has received unprecedented attention due to the opening of the Olympic Games, which will undoubtedly promote and standardize dish name translation, and will also enhance the image and taste of the Chinese catering industry in the world. However, the strategy of translating dish names depends on the purpose of translation, and functional teleology is a better solution. It helps to liberate translators and enhance the direction and practicality of English recipes (Pan, 2007).

He Yuqin has pointed out that the ethnic minorities in Guizhou are affected by the special geographical environment and climatic characteristics and have formed their own unique dietary culture, which is an important part of the ethnic minority culture. With the development of tourism in Guizhou, the characteristics of ethnic minorities have attracted tourists from many other countries to visit. Therefore, proper translation of ethnic minority dishes plays an important role in promoting its culture. In the translation process, the cultural atmosphere of ethnic minorities should be preserved as much as possible on the premise that the meaning is not affected. The article summarizes the translation strategies of Guizhou minority cuisines. The purpose is not only to do a good job in the translation of Guizhou minority cuisines, but also to help foreigners understand food culture of Guizhou better (He, 2011).

Zhu Jingyan also discusses the English translation of Chinese pasta names from the perspective of functional teleology, and pointed out that Chinese pasta had a long history and a wide range of varieties. Although there have been many articles on the English translation of Chinese cuisine names, there are few articles on the English translation of Chinese pasta names. There is no specific research on translation. The author discusses the English translation of Chinese pasta names from the perspective of functional teleology, and combines the dif- 
ferences between Chinese and Western thinking modes to discuss how to translate Chinese pasta names so that they can be better accepted by foreigners ( $\mathrm{Zhu}$, 2012).

Zhu Xiaojing analyzes the current situation of Lingnan's food culture and pointed out that because of its unique geographical location, Lingnan has created good growth conditions for various water and land creatures to inhabit. Therefore, people in Lingnan eat a variety of things, especially "hunted meat", which gives many people from other provinces the impression that Lingnan people eat everything, but few people understand the origin and culture behind this habit. With the progress of the times, Lingnan's food culture industry has been very different from the legacy of ancient times. Through the collection of historical materials and the form of questionnaires, the reasons behind Lingnan people's love of eating "hunted meat" are explored, and the misunderstandings of other provinces regarding Lingnan's food culture are also revealed. It aims to let more readers understand the cultural reasons why Lingnan people "dare to eat" and the changes in Lingnan people's diet (Zhu, 2015).

Liu Caixia takes the Miao nationality's characteristic dishes in the Wuling Mountain area as an example to discuss the translation strategies of ethnic characteristic dishes. She points out that translating national dishes requires deep understanding of their cultural connotations with the help of in-depth description, and the use of proper translation strategies to spread national food culture.

When translating national special dishes, besides the main material, it also needs to reflect the attribute of the nation and reflect the nation's dietary psychology, and reflect the nation's dietary customs. It aims to enrich the translation strategy of dishes, and promote the spread of national food culture (Liu, 2015).

Zhou Qilin conducts a research on the English translation of recipes for ethnic minorities in Guizhou, and proposed to use Skopos theory to free the translator from the shackles of the original text, and then choose translation strategies flexibly according to the expected function and purpose of translation, which is a good solution to the English translation of recipes for ethnic minorities in Guizhou. His suggestions promote the spread of dietary culture of Guizhou ethnic minority greatly (Zhou, 2016).

\section{Cultural Factors Implied in Metaphor-Loaded Dish Names}

In the dietary concept of the Chinese nation, the metaphors of dish names are closely related to culture. In Chinese people's opinions, eating is not only an activity to meet physiological needs, but also an important social and cultural activity. Therefore, people often endow "eating" with rich cultural connotations. While, westerners pay more attention to the actual use of food, that is, the nutrition and calories of food. China's metaphor-loaded dish names are closely related to the traditional culture of the Chinese nation, and this connection is concentrated in the six cultural themes of "Fu, Lu, Shou, Xi, Cai, Ji" (Kuang, 
2010). For example: Haixiantoufubao symbolizes happiness and perfection; Meiweizhashuangpin symbolizes happiness and wealth; Yubishaoluorou symbolizes longevity; Jinxiuxianbei symbolizes the attraction of treasure. Only when the translators grasp these cultural themes presented in the metaphorical dish names, can they truly introduce Chinese food culture to foreign guests through translation.

\section{Problems in the Translation of Metaphor-Loaded Dish Names}

In the existing translation results of metaphorical dish names, there are two extreme phenomena. One is to completely abandon the image and cultural connotation of metaphorical dish names, and translate them into "realistic" dish names, for example, Longfengchengxiang is directly translated into chicken and fish, but the appearance of this dish at the wedding banquet is to bless the newlyweds to have the blessing of dragon and phoenix (which are highly worshiped by Chinese people), and to live peacefully and happily.

The other is to "move" the image of metaphorical dish names directly into the target language regardless of cultural differences. For example: Fotiaoqiang is directly translated into Buddha Jumping over the wall. The name is translated character by character literally, which makes the foreigner feel puzzled. In fact, there is an ancient interesting story related to this dish's name. It is one of the famous dishes in Fuzhou. The story related to this dish is about a monk of Tang Dynasty, who passes by Fuzhou, the "Capital of Fujian", and stays overnight at an inn. It happens that the noble official's house beside the wall serves guests with a "Mantanxiang". Dun abandoned Buddhism for many years of practice, jumped over the wall to enjoy the "full altar incense", "Buddha jumps over the wall" is named after it. Attracted by the smell of the delicious dish, this monk abandons Buddhism which he believes in for many years of practice and jumps over the wall to taste it. "Buddha jumps over the wall" is named after this story.

But these translation methods are not conducive to spread the food culture of the Chinese nation. In response to these two current phenomena, this article puts forward the translation techniques in order to achieve the purpose of avoiding cultural conflicts and facilitating communication between different cultures.

\section{Translation Techniques of Metaphor-Loaded Dish Names}

Under the general trend of globalization, each country gradually attaches importance to its comprehensive national power and cultural soft power. Food culture helps enrich the diversity of Chinese culture, and cultural diversity is an important condition for maintaining cultural ecology and an inexhaustible driving force for the advancement and development of culture itself. Food culture does not only include "eating" and "drinking", it represents people's attitudes towards nature and life, which has rich cultural connotations. The cross 
connection between cultural translation and other disciplines gives cultural translation a macro perspective and a micro-strategy discussion. In the English translation of food culture, attention should be paid to the macro perspective of cultural translation to explore how the national characteristic culture is displayed in the English translation of food culture. But we must fully consider the acceptability of the target language culture and find specific translation strategies to achieve the goal of spreading the Chinese nation's food culture. After analyzing the metaphorical dish names, the following techniques can be used in the process of translation:

First, for dishes named with interesting images, literal translation with pictures should be adopted. For example: "Mayishangshu" can be translated into "the ants climbing up a tree" when translated. Then attach a picture of the dish. In this way, customers can see the image of the dish vividly. In the Chinese name of this dish, Mayi (ants in English) represents minced pork and Shu (tree in English) refers to noodles made from bean or sweet potato starch.

Second, for dishes named by using homophonic means, Pinyin can be directly used to present the name of the dish. For example: "Duiniutanqin" can be named directly with Chinese pinyin. But people who don't understand Chinese culture don't quite understand the meaning of this word, let alone what the ingredients are. In this way, an explanation can be added. Duiniutanqin is an idiom in Chinese. The original meaning of this idiom is to laugh at the person who does not know what the other person is talking about. It is a sarcastic way to blame the speaker who doesn't figure out what kinds of people they are lecturing to. However, the name is taken here because of the beef and celery, which are the ingredients of the dish. Niu in Chinese here refers to beef in English. Qin in Chinese has the same sound as the celery in Pinyin, so the name is homophonic and metaphorical.

Third, for dish names with cultural legends, translators can directly translate their names and add related stories. For example, "Dongpo Rou" can be translated as "Dongpo Pork". Dongpo Pork is a trademark dish of Hangzhou. To eat Dongpo Pork is to begin to understand the role of fat in making meat taste good. The story is like this: Su Dongpo, a great writer in the Song Dynasty, served as an official in Hangzhou twice. The first time he was a judge (1069 AD), and he wrote a lot of popular West Lake poems. In $1088 \mathrm{AD}$, the West Lake was decayed without remediation for a long time, and the government spent a lot of money to renovate the West Lake with no results. The then governor actually wanted to abandon the lake to make land. Su Dongpo once again went to Hangzhou as the new governor which was called Taishou in a critical moment. He led the people in Hangzhou to dredge the West Lake and finally brought the West Lake back to youth. The people in Hangzhou were grateful, beating gongs and drums, carrying pig and dan wine to the prefectural palace. Su Dongpo couldn't refuse, so he had to accept it. Faced with piles of pork, he asked the chef at the house to cut the meat and cook it. The migrant workers tasted the braised pork delivered by Su Taishou, and the taste was unusual. They called it "Dongpo 
Pork".

\section{Conclusion}

In short, from the perspective of cultural translation, the translation of metaphor-loaded dish names is closely related to the differences between Chinese and Western food cultures, and proper translation techniques will promote exchanges between different cultures. Therefore, the translation of metaphor-loaded dish names has a research value that cannot be ignored. It not only helps to better introduce Chinese dishes to foreign friends, but also helps foreign friends to better understand and accept Chinese food culture. Due to limited time, this article is a phased achievement of diet translation research. In terms of diet translation, researchers need to conduct further in-depth research.

\section{Acknowledgements}

The paper is under the project of A Study on the English Translation of Literature on Diet in Taihang Mountain area (Project No. 201803050208) which is sponsored by Social Science Association of Hebei Province. All the project members made their contributions to the paper. I also thank all my friends and classmates who work in different universities, which made the investigation possible.

\section{Conflicts of Interest}

The authors declare no conflicts of interest regarding the publication of this paper.

\section{References}

He, Y. Q. (2011). The Strategy of Translating Cuisines' Names of Ethnic Groups in Guizhou. Journal of Fujian Institute of Education, 3, 102-104.

Kuang, J. H. (2010). Chinese Metaphorical Dishes Names: Their Functions and Language Features. Anhui Literature Journal, 9, 243+263.

Liu, C. X. (2015). A Study on the Translation of Ethnic Dishes: A Case Study of Miao Cuisine. China Translators Journal, 1, 110-113.

Pan, Y. Q. (2007). On the English Translation of Chinese Dish Names from the Perspective of Functional Teleology. Journal of Sichuan Higher Institute of Cuisine, 4, 9-10+26.

Zhou, Q. L. (2016). On the Translation of Guizhou Ethnic Dishes from the Perspective of Skopos Theory. Guizhou Ethnic Studies, 8, 183-185.

Zhu, J. Y. (2012). A Probe into Pasta Name Translation from the Perspective of Skopos Theory. Journal of Jiangxi Institute of Education, 3, 161-165.

Zhu, X. J. (2015). An Analysis of the Status Quo of Lingnan Food Culture. Literature Education (Part 1), 7, 135-137. 